\title{
Decentralised Governance of Wetland Resources in the Lake Victoria Basin of Uganda
}

\author{
Alice Nakiyemba Were ${ }^{1,2}$, Moses Isabirye ${ }^{2}$, Jean Poesen ${ }^{1}$, Miet Maertens ${ }^{1}$, Jozef Deckers ${ }^{1}$, \\ Erik Mathijs ${ }^{1}$ \\ ${ }^{1}$ Department of Earth and Environmental Sciences, Katholieke Universiteit Leuven, Leuven, Belgium; ${ }^{2}$ Faculty of Natural Resources \\ and Environment, Busitema University, Namasagali Campus, Tororo, Uganda. \\ Email: alicenakiyemba@gmail.com
}

Received October $16^{\text {th }}, 2012$; revised November $19^{\text {th }}$, 2012; accepted November $30^{\text {th }}, 2012$

\begin{abstract}
Recent studies on decentralized wetland governance in Uganda have focused mainly on the relationship between central and local governments. Less attention has been given to the relationship between agricultural systems, local governments, and water bodies. This study aims at assessing decentralized wetlands governance in the upper river Rwizi and Iguluibi micro catchments, Lake Victoria Basin Uganda, in relation to farming practices. Qualitative and quantitative methods were used to provide a comprehensive understanding of the contribution of decentralized governance to the management of wetlands resources. Quantitative survey data were analyzed using descriptive summary statistics with the help of Statistical package for Social Sciences (SPSS) soft ware. Qualitative data analysis involved the categorization of verbal and behavioral data for purposes of classification with the use of Nvivo soft ware. Data were analyzed at two levels: the descriptive level of analysis which is the account of the data in terms of what was said, documented or observed with nothing assumed about it. The second level of analysis was interpretive, where data is transformed into what is meant by the responses and conclusions are drawn. All recorded interviews were transcribed into a written report. Findings revealed that decentralized wetlands governance has brought ecosystem services nearer to communities in form of community-based management planning. However, results indicated inadequate institutional capacity, knowledge gaps of existing legal frameworks, limited political support and accountability for local leaders, lack of cooperation and coordination, and inadequate funding. In all, the policy has not fully realized its intended outcomes.
\end{abstract}

Keywords: Agricultural Systems; Decentralized Governance; Lake Victoria; Wetland Degradation; Uganda

\section{Introduction}

Wetlands are one of the most essential resources of Uganda and key components of the riparian areas that filter sediments from runoff thereby minimizing water pollution. However, their environment is increasingly threatened by expansion of agricultural activities because of their food production potential during dry periods. Wetland cultivation has become an important adaptation and coping mechanism to climate change. The wetlands of Lake Victoria Basin in particular, face major environmental problems which include encroachment for the expansion of cropland (Figure 1), and the burning and extraction of papyrus. This is exacerbated by the high annual population growth rate. Besides ecological values like climate regulation and trapping sediments, wetlands in the Lake Victoria Basin also have economic and social values such as fishing and crop cultivation [1]. In 1964, the total area of un-degraded wetlands in Uganda was estimated at $32,000 \mathrm{~km}^{2}$ but by 1999 , it had decreased to
$30,000 \mathrm{~km}^{2}$, (13\% of Uganda's total area), and in 2005, reduced to $26,308 \mathrm{~km}^{2}$, or $11 \%$ of the total area of Uganda [2]. The key underlying causes of this decline is the continuous desire for the population both the rich and the poor to derive livelihoods from the wetlands such as reclamation for agriculture, as well as over harvesting of materials mainly for construction and handicraft. In addition, stakeholders are insufficiently aware of policies concerning the lake and land use. Many laws, policies and regulations governing natural resources and the environment seem to be inadequate to meet today's needs and challenges posed by high population growth rate and intensive agricultural activities. The legal frameworks either encourage full exploitation of resources or lack mechanisms to regulate human activities [3]. The policies often ignore the needs of different stakeholder groups beyond farmers and those involved in other land uses such as private companies. The ten-year wetlands sector strategic plan launched in 2001 (2001-2010) with strategies to achieve sustainable wetlands management is due 


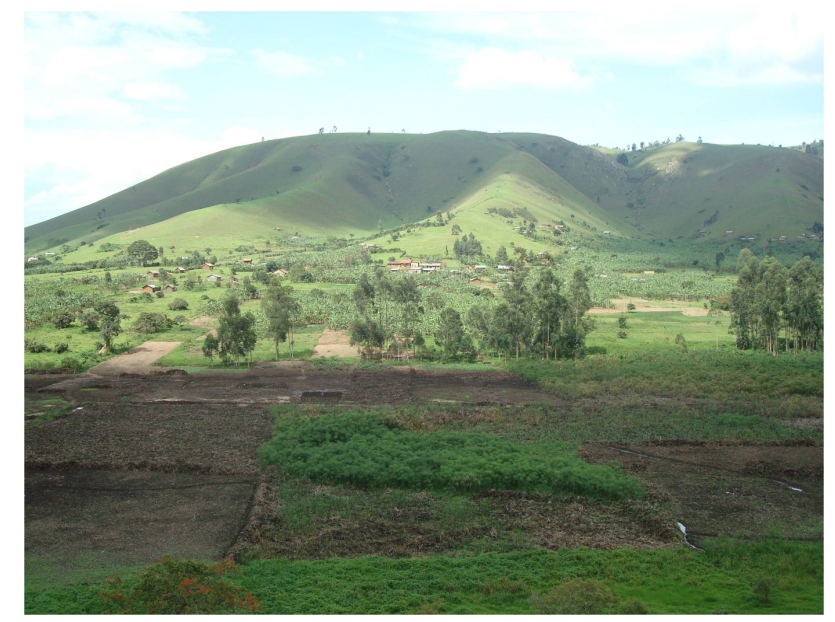

Figure 1. Severly degraded wetland in the Rwizi catchment. Note that the original papyrus vegetation has been cleared almost for the establishment of cropland, eucalyptus trees and local grazing (May, 2009). for review to assess the achievements of its intended outcomes.

This paper starts by describing the wetland degradation, the institutional setup and arrangements of wetland governance in Uganda, and then discusses the inception of decentralized policy and natural resource governance measures that focus on wetlands. We examine two case micro catchments in detail: the upper river Rwizi in Western Uganda and the Iguluibi in Eastern Uganda (Figure 3).

\section{Institutional Setup and Arrangements of Wetland Governance in Uganda}

Prior to 1986, wetlands were not regarded as important resources and were referred to as wastelands [4]. No institution had the mandate to deal with wetland issues. Many of the wetlands were communally owned and local communities had local bylaws governing them. In the nineteenth century, Uganda was declared a British

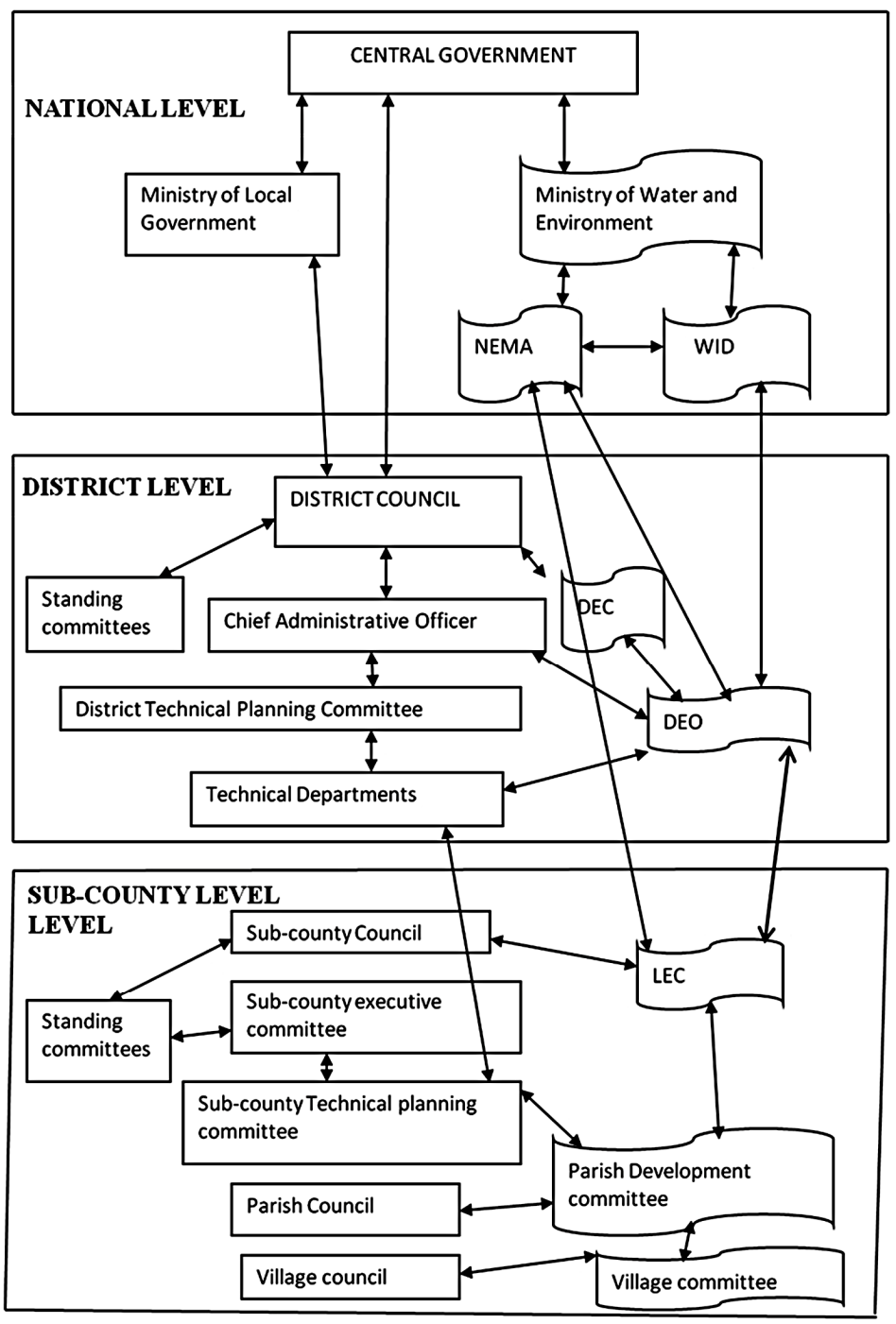

Figure 2. Decentralized wetland governance structures in Uganda [12]. 
protectorate and wetlands were governed directly by British law. During the post independence era (19621971), wetlands were centralized and maintained in reasonably good condition [4]. Fundamental changes were introduced in 1975 by way of the "Land Reform Decree", which declared all land in Uganda as public land to be managed by the Uganda Land Commission (ULC). Then, there was political instability and no effective natural resource management which resulted into resource degradation $[4,5]$.

Since 1980, decentralization has been looked at as a solution to many of the governance problems constraining local and national development [6]. The increasing interest in decentralized governance policy resulted from calls for greater democratization, accountability and efficiency from international organizations as well as local civil society [7]. Decentralization involves bringing governments closer to the governed, so that it is easier to hold local leaders accountable [6]. Drivers of decentralization could be to implement a neoliberal policy diminishing the state's influence or to distribute power and financial resources among citizens which is critical to sustainable natural resource governance. Decentralization assumes that local actors will be more incentivized to respond to interventions if they are given greater control over the design and implementation of conservation programs [8]. However, there is no guarantee that once local people are empowered there will be no conflict with the way these mechanisms are put in practice.

When the National Resistance Movement (NRM) took over power in 1986, the State introduced natural resource governance that emphasized decentralization through various institutions and legal frameworks. In 1986 the Ministry of Lands and Environmental Protection was put in place to deal with environmental issues and to protect wetlands. In 1989, the National Wetlands Program (NWP) was established as a mechanism to formulate a national policy for the conservation and management of wetlands. Then in 1995 [9], constitutional reforms brought about major changes in environmental management. Decentralization established a new institutional framework (Figure 2). The notion of wetlands being referred to as wastelands has apparently changed. Over the last 20 years, the wetland resources have been put under considerable pressure from agriculture due to population increase resulting in the draining of many wetlands and the modification of several others. The key stakeholders involved in wetland governance include user communities living adjacent to wetlands such as farmers who drain wetlands for grazing and crop production, papyrus harvestors, brick and charcoal burners, Local and Central governments, politicians, and indigenous institutions. The attitudes and decisions of these stakeholders are the key determinants to the successful implementation of wetland policy.

At the center of this policy shift, the National Decentralization Policy involved the review and realignment of the environment and natural resources regulation. Through the Local Government Act of 1997 [10], the central government's powers and responsibilities were passed on to the local governments. Two institutions were created to coordinate natural resource management: the National Environment Management Authority (NEMA) established in 1995 by the National Environment Act (NEA) as a semi-autonomous institution to coordinate, monitor, regulate and supervise all matters on environmental management in Uganda. The Wetlands Inspection Division (WID) of the Ministry of Water and Environment is mandated to regulate and control wetland use activities after enactment by parliament [8]. At the district level (second administrative unit to the central government), the transfer of rights and responsibilities to the local level was organized through the new mandate of NEMA that established the District Environmental Office (DEO). At subcounty level (third administrative unit to the central government), the LECs are appointed under the NEA of 1995 [11] and are mandated with the following functions: prepare local environment work plans; mobilize the people to conserve natural resources through voluntary selfhelp such as planting trees, and monitor all environmental activities in the community. However, though the Parish and village level structures have been put in place; they have not been fully operationalized. In addition, the county level is not an administrative structure for wetland governance [11].

The purpose of this paper is to establish whether the decentralized wetland policy is being implemented properly, and in the process achieving its intended benefits as a response to the problem of wetland degradation. For this, we focused on two catchments of the Lake Victoria Basin, namely the upper river Rwizi and the Iguluibi micro catchments. We further analyze the involvement and power relations of different stakeholders, as these affect the governance and the management of wetland systems. Putting the focus on the governance systems of wetland resources is crucial in deterring further wetland degradation particularly in the Lake Victoria Basin. Our study is timely as it has been over 15 years since Uganda's wetland policy and decentralized wetlands governance were established as foundations for more sustainable wetland management.

\section{Materials and Methods}

\subsection{Description of the Study Sites}

To analyze the decentralization of wetland resources governance, we chose two case studies in the riparian areas of the Iguluibi and the upper river Rwizi micro catch- 
ments of the Lake Victoria Basin (Figure 3). These catchments are representative for the lake basin in terms of geology and geomorphology, soils, climate, vegetation and land use [12]. The study areas are characterized by a bimodal rainfall, one in the months of March through to May, and the other from September to December with a mean annual precipitation of $1283 \mathrm{~mm}$ recorded over the last 40 years $[13,14]$. Both areas are dominated by intensive mixed agriculture consisting of banana-coffee systems with maize, beans and sweet potatoes as annual crops. Livestock keeping is more extensive in the upper river Rwizi micro catchment than in the Iguluibi micro catchment.

The Iguluibi micro catchment is located in the Mayuge district of Uganda, north of the lake. It covers $1593 \mathrm{~km}^{2}$, i.e. $5.2 \%$ of the Lake Victoria catchment in Uganda. Many residents in the Iguluibi micro catchment are changing from growing traditional crops to sugarcane due to the proximity to the Kakira sugar factory of the Madhivan company group. Fishing is an important offfarm activity with Tilapia (Tilapia nilotica) and Nile Perch (Lates niloticus) as the most favored species [15].
The Rwizi micro catchment is located in the Mbarara district, west of Lake Victoria. It covers $2070 \mathrm{~km}^{2}$ of the lake catchment in Uganda. The Rwizi micro catchment is supplied by the river Rwizi, which begins in the Buhweju hills in the Bushenyi district and flows east through a number of papyrus swamps eventually discharging into Lake Victoria through the river Bukora and the Sango plains. The Rwizi gets water from the Itojo wetland system (Ntungamo), the Bujaga wetland (Mbarara), the Nyakambu wetland (Bushenyi) and the Kooga wetland system (Kashari). These wetland systems are naturally replenished by the water sources in the ridges of Buhwa, Bucuro, Ryengoma, and Rubindi. The hill slopes in the Rwizi micro catchment, mostly bare of trees, are predominantly used as pasture land for grazing livestock. However, burning of rangelands and the expansion of livestock keeping into the wetlands, especially during the dry season, is now common practice [5]. Foot slopes are planted with bananas, sometimes intercropped with coffee and other crops such as beans, and maize. Natural vegetation, mainly papyrus and reeds, cover the lowlands.

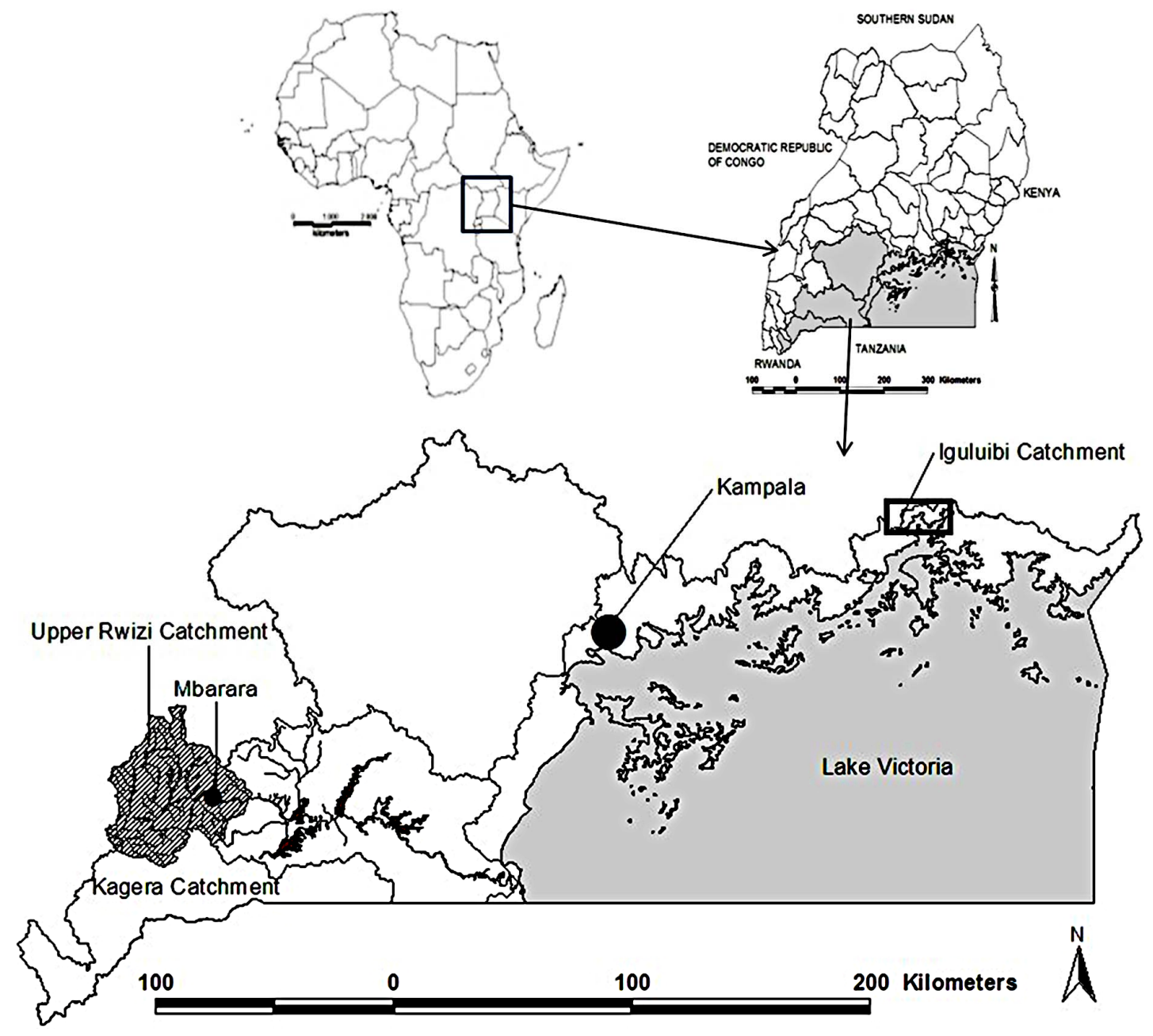

Figure 3. Lake Victoria Basin showing the Rwizi and Iguluibi catchments. 


\subsection{Methods}

We applied a mixed method approach including both qualitative and quantitative surveying techniques to assess the contribution of decentralized governance to the management of wetland resources in the Iguluibi and upper river Rwizi micro catchments [16]. Mixed methods are very useful when examining complex systems such as social-ecological system.

Survey data were collected from a sample of 150 farmers who were selected from a three-stage stratified random sampling design. In the first stage, five sub-counties were randomly selected (two from Iguluibi and three from the upper river Rwizi) and in a second stage, 15 villages in these sub-counties were selected. For the final sampling stage, households were stratified according to whether they use wetlands for expansion of crop land or animal grazing or not and 10 households per selected village were selected from both strata. A list of all residents in the selected villages was used to identify all farmers using wetlands and those not using wetlands and then a systematic random sampling interval was used to select the 10 households. The total study population was 540 respondents. The interval for systematic selection was arrived at by dividing the number of farmers using and not using wetlands by the sample needed per village. We used a semi-structured questionnaire to capture issues such as current practice of decentralization, accountability issues, power relations among stakeholders, and legal frameworks governing decentralized wetland resources among others. The response rate during the survey was $100 \%$, which might be due to the fact that enumerators were experienced researchers and were familiar with the local language and community setting. Enumerators conducted the survey interviews and the researchers conducted the focus group discussions and key informant interviews. For communities where the researchers could not speak the local language, enumerators translated the interviews. Data was transcribed by the entire research team.

In addition, qualitative interviews were conducted, targeting leadership at the local level, to collect in-depth information of the benefits of the policy in the two study sites. For this, we selected 30 key informants, including local council leaders, extension officers, environment officers, agricultural officers, politicians, and local environment committees for individual interviews. In addition, we organized 3 focus group discussions in each of the 15 selected villages, including 8 farmers per group with homogenous characteristics. Also complementary secondary data from scientific reports were used as additional sources of information (Uganda Bureau of Statistics, Constitution of Uganda 1995, Local government Act 1997). A data code sheet was developed and used to code the data uniformly for data entry purposes. Quantitative survey data were entered and analyzed using descriptive summary statistics with the help of Statistical package for Social Sciences (SPSS) soft ware was to report all quantitative information. Frequencies and percentages were calculated to facilitate the drawing up of inferences related to wetland governance. Qualitative data analysis involves the categorization of verbal and behavioral data for purposes of classification with the use of Nvivo soft ware. Data were analyzed at two levels: the descriptive level of analysis - which is the account of the data in terms of what was said, documented or observed with nothing assumed about it. The second level of analysis was interpretive-where data is transformed into what is meant by the responses and conclusions are drawn. All recorded interviews were transcribed into a written report.

\section{Results}

Over 15 years, institutional frameworks for decentralized wetland governance have been developed but there are a number of weaknesses in implementing these frameworks. Our findings show that in both study catchments, the DECs and the LECs do not function well. Study findings further reveal that farmers in the study areas are highly dependent on wetlands for their livelihoods. This high dependence makes it difficult to realize the expected benefits of the policy. Policy failures include a lack of institutional capacity, poor cooperation and coordination at the various local government levels, a lack of political support, lack of sensitization of farmers, inadequate funding and poor accountability by local leaders.

\subsection{Lack of Institutional Capacity}

In all the 15 villages, we identified a lack of institutional capacity to manage wetlands, as the district technical staff is still struggling to understand and implement the relevant legal frameworks. Decentralization of natural resources in Uganda is mandated by the following key legal instruments: the 1995 Constitution of the Republic of Uganda; the 1995 National Environment Act (NEA); the 1997 Local Government Act; and the National Environmental Management Act 2000. The LECs have been appointed, but the District Environment Officers said their capacity has been inadequately developed in environmental governance. In the Iguluibi micro catchment where it was indicated that minimal efforts have been undertaken, while some elements of public environmental education have been conducted in the Rwizi micro catchment as indicated in Table 1. Our qualitative interviews highlighted that local committees have not received sufficient training to enable them execute their duties and some confessed to having not known their roles. The DECs face a challenge of understanding and 
Table 1. Farmers' knowledge of Legal Frameworks governing wetlands in the community calculated from survey data. \# is number of farmers.

\begin{tabular}{|c|c|c|c|c|c|c|c|c|c|c|c|c|c|c|}
\hline \multirow[t]{3}{*}{ Legal frameworks } & \multicolumn{6}{|c|}{ Iguluibi } & \multicolumn{6}{|c|}{ Rwizi } & \multirow{2}{*}{\multicolumn{2}{|c|}{ Grand total }} \\
\hline & \multicolumn{2}{|c|}{ Female } & \multicolumn{2}{|c|}{ Male } & \multicolumn{2}{|c|}{ Total } & \multicolumn{2}{|c|}{ Female } & \multicolumn{2}{|c|}{ Male } & \multicolumn{2}{|c|}{ Total } & & \\
\hline & $\#$ & $\%$ & $\#$ & $\%$ & $\#$ & $\%$ & \# & $\%$ & $\#$ & $\%$ & $\#$ & $\%$ & $\#$ & $\%$ \\
\hline Not aware & 33 & 22.0 & 18 & 12.0 & 51 & 34.0 & 15 & 10.0 & 10 & 6.7 & 25 & 16.7 & 76 & 50.7 \\
\hline Not existing & 4 & 2.7 & 1 & 0.7 & 5 & 3.3 & 21 & 14.0 & 26 & 17.3 & 47 & 31.3 & 52 & 34.7 \\
\hline Existing & 9 & 6.0 & 3 & 2.0 & 12 & 8.0 & 2 & 1.3 & 8 & 5.3 & 10 & 6.7 & 22 & 14.7 \\
\hline Total & 46 & 30.7 & 22 & 14.7 & 68 & 45.3 & 38 & 25.3 & 44 & 29.3 & 82 & 54.7 & 150 & 100.0 \\
\hline
\end{tabular}

deliberating on technical issues of the environment and natural resources without adequate technical capacity considering the low levels of education of most of these councilors. This has facilitated continuous encroachment on wetlands because farmers cannot receive information required to fully understand issues of wetland conservation. Inadequate information were reported by district technical staff as a result of inadequate finance and human resources which does not allow trainings for all farmers but focus on key leaders in the community. In addition, it was reported that the departments of environment and natural resources at the districts have only one District Environment Officer, without an assistant who has to travel to all the subcounties in the district when all logistics fail; only attends to areas where there are problems.

\subsection{Poor Sensitization of Farmers}

Our findings also revealed poor sensitization of farmers as manifested in poor understanding of existing legal frameworks and threats to wetlands use in the two micro catchments. For example, 75\% of the Iguluibi catchment farmers are not aware of any legal frameworks concerning wetland conservation, compared to only $30 \%$ in Rwizi micro catchment. Farmers were not aware of the property rights governing wetland conservation. Quantitative data further shows that $50.7 \%$ of the farmers were not aware of existing laws, rules and regulations governing decentralized wetland resources, while $34.7 \%$ said the legal frameworks do not exist (Table 1). Only 14.7\% said legal frameworks exist and these were a few farmers that owned or had access to a radio, or had attended a meeting where such legal frameworks were discussed. Findings from focus group discussions indicate that few farmers are aware of the decentralized wetland policy. Farmers said that policies and regulations governing wetlands have not been implemented at the local levels and that some of the impeding factors are political [17]. Have stressed that since the conservation and sustainable use of wetland resources rely mainly on farmers and other users living in settlements close to wetlands, these people should become key stakeholders in a wetland conservation agenda. It is important for environmental policy-makers, District Environment Officers, Agricultural extension officers and politicians to adequately know the opinions and attitudes of farmers regarding environmental issues and practices affecting wetlands. In most cases, when dealing with a new policy it is important that the target stakeholders be sensitized to it, and its implications, before it is implemented. In this case, more attention should be paid to the farmers who are most affected by the policy, but who may have limited channels of communication, to ensure that farmers are sensitized about the dangers of clearing wetlands for agricultural expansion and its implications to the Lake Victoria waters. Community in general should be heard in local policy and their knowledge and practices should be included in the local policies.

\subsection{Impact Realized by Stakeholders since Inception of the Decentralized Wetland Policy}

In general, most farmers reported to have not noticed any visible positive impact from decentralized wetland governance $(58.7 \%, n=88)$. Only $29.3 \%(n=44)$ said noticed a positive impact and these could be most likely farmers who have been involved in training or implementing National Agricultural Advisory Services (NAADS) activities.

Most respondents noticed a negative impact of decentralization. Weak government policies and poor implementation procedures ranked highest $(45.9 \%, \mathrm{n}=17)$, followed by conflict of interest and corruption (32.4\%, $n$ = 12) (Table 2). Interviews held with district technical staff revealed some positive outcomes of the policy, communities can now participate in the action plans although, it is not easy to stick to the plans in view of other local political interests, due to a problem of scales perception and interest of class. This implies a weak impetus to implement natural resource conservation policies.

This is in agreement with previous findings [17]. This calls for a need to strengthening regulations and enforcement mechanisms that ensure proper management 
Table 2. Reported reasons for farmers to consider observed policy changes to be negative calculated from survey data with multiple responses. \# is number of farmers.

\begin{tabular}{|c|c|c|c|c|c|c|}
\hline \multirow{2}{*}{ Reasons for negative changes } & \multicolumn{2}{|c|}{ Iguluibi } & \multicolumn{2}{|c|}{ Rwizi } & \multicolumn{2}{|c|}{ Total } \\
\hline & $\#$ & $\%$ & $\#$ & $\%$ & $\#$ & $\%$ \\
\hline Weak government policies \& implementation & 4 & 10.8 & 13 & 35.1 & 17 & 45.9 \\
\hline Conflict of interest and corruption & & 0.0 & 12 & 32.4 & 12 & 32.4 \\
\hline Poor sensitization of farmers & 6 & 16.2 & & 0.0 & 6 & 16.2 \\
\hline Population pressure & 2 & 5.4 & 3 & 8.1 & 5 & 13.5 \\
\hline Don't care attitude & 1 & 2.7 & 2 & 5.4 & 3 & 8.1 \\
\hline Poor government planning & 1 & 2.7 & 1 & 2.7 & 2 & 5.4 \\
\hline Lack of knowledge & & 0.0 & 1 & 2.7 & 1 & 2.7 \\
\hline Total & 10 & 37.8 & 7 & 86.4 & 46 & 124.2 \\
\hline
\end{tabular}

of government policies, reducing conflict of interest and corruption.

\subsection{Lack of Political Support}

Political support can be a facilitating factor to the sustainable management of natural resources. In this study, we found lack of political support at the local government levels is one of the factors constraining decentralized wetland governance.

Local level leaders, for example, find a challenge in implementing policy because farmers are using wetlands to produce food for their food insecure families. Through the focus group discussions we found that village leaders who have received public environmental education are not willing to disseminate such information to farmers for political reasons. This is mainly due to fear that they may not be popular with the electorate when seeking re-election. Furthermore, technical staff said they experience the challenge of bureaucracy when conducting policy interventions. For example, the chairperson of the District Council has to be informed; then, the area councilor before any intervention takes place. This implies that the councilor is likely to protect interests of the electorate in case the policy negatively impacts on them. But the technical staffs, especially in the Rwizi micro catchment, feel that some farmers know the policies and regulations governing wetlands but are being protected by politicians when they encroach upon the wetlands. They argue that when politicians see an opportunity to stay in power they seize it even if it means allowing farmers to encroach on wetlands as long as people can keep on voting them in power. The multiple roles of local leaders of ensuring wetland conservation, food security and protecting interests of the electorate whose livelihood solely depend on the use of wetlands is challenging and there is a tendency to compromise on wetland conservation in favor of food production and political interests. It was mentioned that in most villages, farmers listen more to politicians than implementers and this has facilitated wetland degradation. In general, the relatively recent history of democracy in Uganda has had a possible influence on the lack of political support.

\subsection{Lack of Accountability for Leaders to Decentralized Wetland Management}

Most farmers $66.7 \%$ indicate that local leaders do not feel accountable for wetland management, while $18.0 \%$ said the leaders do feel accountable (Table 3). Interviews with various local government leaders on the issue of accountability for sustainable wetland resources in the Iguluibi catchment resulted in mixed insights. Whereas $68 \%$ of district leaders feel accountable, $58 \%$ of the lower local government leaders do not feel responsible and say policy failures have been due to lack of information dissemination. All village council leaders in the 15 villages did not feel accountable because they have not been sensitized about wetland conservation issues.

On the other hand, local government leaders in the Upper river Rwizi catchment said that they do feel accountable because they know the farming practices that contribute to the degradation of wetlands but have not taken up their responsibilities to educate farmers or develop appropriate interventions. They said farmers used to get papyrus grass from wetlands to use as mulch, but now the wetlands have been fenced off for extensive catle grazing by the rich farmers. This has resulted into conflict between small and large landowners, or between papyrus users and cattle economical segments. The banana plantations close to the river have no soil conservation structures in place and this has led to increased soil erosion, which eventually has affected the water quality of river Rwizi. These findings concur with Karl Marx (1818-1883) a sociological thinker with his conflict theory [18], who noted that the growing concentration of ownership of land and productive resources (including capital) affected how economies worked and gave rise to classes of wealth and classes of poor, to inequalities of all kinds, and to decisive political control by wealthy 
Table 3. Farmers' perception about the accountability of local leaders towards wetland management calculated from survey data. \# is of farmers.

\begin{tabular}{|c|c|c|c|c|c|c|c|c|c|c|c|c|c|c|}
\hline \multirow[t]{3}{*}{ Accountability of local leaders } & \multicolumn{6}{|c|}{ Iguluibi } & \multicolumn{6}{|c|}{ Rwizi } & \multirow{2}{*}{\multicolumn{2}{|c|}{$\begin{array}{c}\text { Grand } \\
\text { Total }\end{array}$}} \\
\hline & \multicolumn{2}{|c|}{ Female } & \multicolumn{2}{|c|}{ Male } & \multicolumn{2}{|c|}{ Total } & \multicolumn{2}{|c|}{ Female } & \multicolumn{2}{|c|}{ Male } & \multicolumn{2}{|c|}{ Total } & & \\
\hline & $\#$ & $\%$ & $\#$ & $\%$ & $\#$ & $\%$ & $\#$ & $\%$ & $\#$ & $\%$ & $\#$ & $\%$ & $\#$ & $\%$ \\
\hline Do not feel accountable & 35 & 23.3 & 17 & 11.3 & 52 & 34.7 & 26 & 17.3 & 22 & 14.7 & 48 & 32.0 & 100 & 66.7 \\
\hline Feel accountable & 8 & 5.3 & 3 & 2.0 & 11 & 7.3 & 8 & 5.3 & 8 & 5.3 & 16 & 10.7 & 27 & 18 \\
\hline Do not know & 3 & 2.0 & 2 & 1.3 & 5 & 3.3 & 4 & 2.7 & 14 & 9.3 & 18 & 12.0 & 23 & 15.3 \\
\hline Total & 46 & 30.7 & 22 & 14.7 & 68 & 45.3 & 38 & 25.3 & 44 & 29.3 & 82 & 54.7 & 150 & 100.0 \\
\hline
\end{tabular}

classes. In his view, culture simply represents the material interests of the dominant economic classes.

Farmers also mentioned several reasons why they thought local government leaders are not accountable including: 1) leaders do not care about people but are concerned about their votes; 2) lack knowledge of wetland management; 3 ) they are encroaching on wetlands themselves; 4) they lack the facilitation to execute their duties; 5) enforcement mechanisms are poor and there is corruption; 6) NEMA does not supervise the local leaders; and 7) political leaders fear to do what is unpopular even if it is right, because it will affect their political capital. If decentralized management of wetlands is to be achieved for the benefit of Lake Victoria, the government needs the political will and accountability of leaders at all levels of environmental governance.

\subsection{Lack of Cooperation, Coordination among the Various Actors}

Coordination was assessed between farmers and the local governments and among the various local governments to find out the interactions among the various actors. Most farmers (45.3\%) rated the coordination of wetlands issues at local level as poor, while $20.7 \%$ rated it very poor. Only $17.3 \%$ rated it good. Interviews with district officials revealed that there is coordination between the district and the various local governments. Circulars of Natural Resource laws and regulations are sent out to Village council chairpersons in the district through the secretary for environment and production. The greatest challenge facing this channel of coordination is when these leaders have to take information to the farmers where they have conflicting political interests. As a result of poor coordination among the various actors, farmers are not aware of the policies and regulations governing wetland resources. Interviews conducted with staff at the national level indicate that coordination is still a big challenge because different institutions have got different mandates, different levels of authority.

In both catchments, it was reported that communitybased management systems have indeed been developed, as technical staff have agreed upon cultivation, conserva- tion and grazing areas together with the local communities. In the Rwizi micro catchment, the four districts which make up the catchment (Mbarara, Bushenyi, Ntungamo, kiruhura) were brought together to develop a management framework to conserve wetlands and to reduce water pollution. In the community management plan technical staffs demonstrate micro projects of how to use resources sustainably so that the farmers can also improve on their livelihoods. The danger is that most of these plans are in theory and have not had effective impact on wetland conservation due to inadequate human and financial resources.

\subsection{Policies Enacted at Community Level Compared to Policies Enacted at Central Level}

Farmers were asked to compare bylaws and policies enacted at the community level to those centrally enacted. Most respondents said that if the decentralized wetland policy is to be effective, then bylaws and regulations should originate at the community level involving all farmers and thereafter formalized at higher levels. Topdown policies and regulations will have less impact and may not be easily enforced. If policies are enacted at village level then the element of monitoring will be easy because the checks and balances will be done at village level and community needs will be addressed. [19] stresses that although government policies on wetlands embrace the idea of multi-stakeholder participation in wetland management for local, national and international sustainable development agendas, rarely has the debate involved any serious discussion of local community needs or the institutional arrangements developed by communities to achieve the goals.

\section{Discussion}

It is more than 20 years since the introduction of decentralization reforms in Uganda and over 15 years since Uganda's decentralized wetland policy was included in these reforms and these policies have yielded several positive results: improvements in service delivery, increased political participation and accountability by local 
politicians. However, the level of participation among all stakeholders must be further strengthened [8]. With decentralized policies, the intended outcomes seem to be limited and vary from one district to another. Instead of generating more participation of local government, decentralization has allowed politicians to control resources creating a gap between the rich and poor. Instead of becoming more efficient, wetland conservation has declined due to lack of institutional and technical capacity at local levels to perform tasks; poor cooperation and coordination, poor sensitization of farmers, inadequate funding of activities, poor accountability by local leaders and lack of political support. [7] stresses that to benefit from decentralization, policies must do more than simply transfer authority and responsibility from one institution to another but instead must develop the professional capacity, financial resources and political support to deliver the services effectively.

The limited impact can be explained as a result of the insufficient capacity of farmers in terms of information and lack of finance and human resources. [10] found a great deal of energy has been devoted to strengthening local capacity through training and focused support for elected officials and administrative staff in Uganda. They state that environmental governance cannot be reduced to the individual qualities of local actors such as local councilors and administrative staff, but more on the incentives created by the institutional environment in which they have to operate. Instead of focusing on the individual as many of the capacity building projects do in Uganda, two other levels should be considered: 1) the institutional level where government structures arrange local environmental management; and 2) the system level, where the policy and legal frameworks direct local environmental policy. [20] noted that many studies on decentralized natural resource management often concentrate so intently on what is happening at the local level that they fail to relate this explicitly to the wider socioeconomic and political context in which the local is situated. They further say inadequate attention is paid to the fact that what happens at the local level is firmly embedded within broader structures. It is further complicated because many demands for decentralization have stemmed from the international level. Increasingly the question is whether this represents a true shift toward local empowerment or whether it merely reinforces international priorities. [8] noted that many environmental problems in Uganda are simultaneously part of other policy domains, such as agriculture as a result of soil erosion and loss of soil fertility. Addressing these problems requires collaboration between environment and natural resource management and other policy domains to avoid the limitations of curving out a specific domain for environmental policy.

\section{Conclusions}

Based on findings from the study, the decentralized governance of wetlands is not being implemented properly and therefore has not realized its intended benefits. The key stakeholders responsible for governance of wetland resources include user communities living adjacent to wetlands such as farmers, commercial papyrus dealers, brick makers, Local and Central governments, politicians, and indigenous institutions. These stakeholders have different degrees of power to control decisions that have effects on decentralized wetland policy and society at large. They also have different degrees of potential to contribute to achieving intended benefits of the policy. The position of politicians and government gives them more power than other stakeholders. Potential to affect intended benefits is vested on the knowledge and rights that stakeholders hold over others. The governments have financial power while farmers and commercial papyrus dealers have less power, but have high potential and experience of wetland use; hence they all become important and influential to wetland governance. Politicians and the government have more power and influence decisions than other stakeholders at the policy level, while most of the stakeholders at the district level have more power and influence at implementation level. The needs, problems, and interests of stakeholders are the most important for the decentralized wetland policy to succeed. In order to successfully implement the decentralized governance of wetland policy for the conservation and management of wetland resources, stakeholders must be strong, organized, and well funded. Politicians at the various levels must commit themselves to enforcing the decentralized wetland policy even if it makes them unpopular or deprive them of the wealth they would gain. There is need to devote more resources to wetland research to ensure that the policy gets the intended results. Further, community-based management approaches should be strengthened so that wetlands are conserved through community bylaws, then improving existing government programs such as NAADS (National Agricultural Advisory Services) which are trying to improve farming systems and practices implemented by local government authorities. Having dedicated institutions is not enough; all stakeholders must be committed and should stop looking at short-term gains and begin acting in ways that protect wetlands for future generations. Uganda as a country should remain committed to a proper implementation of the decentralized wetlands policy because wetlands constitute an important component of National development due to their ecological and social functions; they provide enormous benefits to the people of Uganda.

\section{Acknowledgements}

The authors wish to thank Joshua Mudusu, Twalaba Er- 
isa, Bahati Joram, Rwobusingye Erias and Thomas Oyabba for their support during data collection. Funding for this study was provided by Belgian Technical Cooperation (BTC), VLIR-OI RIPaVic project Uganda. Farmers and Local leaders are greatly acknowledged for their cooperation and willingness to provide necessary information for the study.

\section{REFERENCES}

[1] NEMA, "National State of the Environment Report, 2006/2007,” National Environment Management Authority, Kampala, 2007.

[2] NEMA, "Wetlands for Forests," World Wetlands Day of 2nd February, Kampala, 2011.

[3] L. H. Lung'ayia and S. M. Kenyanya, "The Nutrient Enrichment of Lake Victoria (Kenya Waters), Kenya,” Hydrobiologia, Vol. 458, No. 1-3, 2001, pp. 75-82. doi:10.1023/A:1013128027773

[4] J. Hartter and J. S. Ryan, “Top-Down or Bottom-Up? Decentralization, Natural Resource Management, and Usufruct Rights in the Forests and Wetlands of Western Uganda,” Land Use Policy, Vol. 27, No. 3, 2010, pp. 815826. doi:10.1016/j.landusepol.2009.11.001

[5] J. M. B. Tukahirwa, "Policies, People and Land Use Change in Uganda: A Case Study in Ntungamo, Lake Mburo and Sango Bay Sites, Land Use Change, Impacts and Dynamics,” Project Working Paper No. 17, International Livestock Research Institute, Nairobi, 2002.

[6] C. Béné, E., Belal, O. M. Baba, S. Ovie, A. Raji, I. Malasha, F. Njaya, M. Andi, A. Russel and A. Neiland, "Power Struggle, Dispute and Alliance over Local Resources: Analyzing 'Democratic' Decentralization of Natural Resources through the Lenses of Africa Inland Fisheries," World Development, Vol. 37, No. 12, 2009, pp. 1935-1950. doi:10.1016/j.worlddev.2009.05.003

[7] J. Antonio and P. Oliveira, "Implementing Environmental Policies in Developing Countries through Decentralization: The Case of Protected Areas in Bahia, Brazil," World Development, Vol. 30, No. 10, 2002, pp. 17131736. doi:10.1016/S0305-750X(02)00067-0

[8] P. Oosterveer and V. B. Vliet, "Environmental Systems and Local Actors: Decentralizing Environmental Policy in
Uganda,” Environmental Management, Vol. 45, No. 2, 2010, pp. 284-295. doi:10.1007/s00267-009-9423-4

[9] "The Constitution of the Republic of Uganda," The Uganda Printing and Publishing Corporation Entebbe, Uganda, 1995.

[10] “The Local Government Act,” Uganda Printing and Publishing Corporation Entebbe, Uganda, 1997.

[11] “The National Environment Act," Uganda Printing and Publishing Corporation Entebbe, Uganda, 1995.

[12] LVEMP, “About Lake Victoria,” 2004. http://www.lvemp.org/

[13] Uganda Department of Meteorology, Government of Uganda, 2000.

[14] M. Isabirye, G. Ruysschaert, L. Van linden, J. Poesen, M. K. Magunda and J. Deckers, "Soil Losses Due to Cassava and Sweet Potato Harvesting: A Case Study from Low Input Traditional Agriculture," Soil and Tillage Research, Vol. 92, No. 1-2, 2007, pp. 96-103. doi:10.1016/j.still.2006.01.013

[15] UBOS, "Uganda National Household Survey 1999/2000; Report on the Socio-Economic," Uganda Bureau of statistics, Entebbe, 2001.

[16] J. J. Kashaigili and A. M. Majaliwa, "Intergrated Assessment of Land Use and Cover Changes in the Malagarasi River Catchment in Tanzania,” Physics and Chemistry of the Earth Parts A/B/C, Vol. 35, No. 13-14, 2010, pp. 730-741. doi:10.1016/j.pce.2010.07.030

[17] M. Pyrovetsi and G. Daoutopoulos, "Contrasts in Conservation Attitudes and Agricultural Practices between Farmers Operating in Wetlands and a Plain in Macedonia, Greece,” Environmental Conservation, Vol. 24, No. 1, 1997, pp. 76-82. doi:10.1017/S037689299700012X

[18] C. L. Harper, "Environment and Society, Human Perspectives on Environmental Issues,” 2nd Edition, Prentice Hall, Inc., Upper Saddle River, 2001.

[19] R. Maconachie, B. A. Dixon and A. Wood, "Decentralization and Local Institutional Arrangements for Wetland Management in Ethiopia and Sierra Leone," Applied Geography, Vol. 29, No. 2, 2009, pp. 269-279.

[20] L. C. Stringer, C. Twyman and D. S. G. Thomas, "Combating Land Degradation through Participatory Means: The Case of Swaziland," Royal Swedish Academy of Sciences Report, Vol. 36, No. 5, 2007, pp. 387-393. 